\title{
A new survey design for 3D IP inversion modelling at Copper Hill
}

\author{
$\begin{array}{llll}\text { R.M.S. White } & \text { S. Collins } & & \text { R. Denne } \\ & \text { R. Hee } & \text { P. Brown }\end{array}$
}

Key words: 3D inversion, IP, Resistivity, Arrays, Copper Hill

\begin{abstract}
The Copper Hill prospect in NSW is a porphyry copper/gold system. Geochemical and gradient array IP results suggest that grid northwest and grid northeast structural directions control the location of mineralisation. Previous drilling has been oblique to these directions.
\end{abstract}

The known sulphide rich mineralised zones exhibit moderate to strong IP responses. An IP/resistivity survey was conducted to produce a detailed 3D mineralisation model for Copper Hill. 3D inversion of IP data is considered suitable for mapping the sulphide horizons in detail.

The use of 3D-inversion modeling techniques, accepting a modified pole-dipole IP survey array, allowed an electrode array to be designed for fast acquisition of a large quantity of data.

The use of modified pole-dipole arrays extend the effective depth of investigation of IP surveys as well as improving the across line resolution.

Inversion results delineated the three dimensional form of sulphides zones at Copper Hill.

\section{INTRODUCTION}

Copper Hill, located $5 \mathrm{~km}$ north of the township of Molong in the central west of NSW, is the first recognised porphyry system in New South Wales. The Copper Hill open pit is the oldest copper mine in NSW with mining commencing in 1845. Up till 1851 a total of 3300 tonnes of ore averaging $1.4 \%$ copper was mined from the enriched supergene zone. Minor copper production was recorded in 1885, 1908-09 and 1919-31. Gold was discovered in 1851 with 14 tonnes, at an average grade of $6.12 \mathrm{~g} / \mathrm{t}$ gold, being mined (Erceg, 1992).

Tooronga Resources Pty Ltd

207 Tooronga Road

Terrey Hills, NSW. 2084

rwhite@tooronga.com

2 Arctan Services Pty. Ltd.

9 Marshall Avenue

Warrawee NSW 2074

scollins@arctan.com.au

3 Golden Cross Operations Pty. Ltd

1st flr, 22 Edgeworth David Ave

Hornsby, NSW, 2077

gcr@dot.net.au

4 Scintrex Pty. Ltd

20 Century Road

Malaga, WA, 6090

splqld@scintrex.aust.com
Approximately $1 \mathrm{~km}$ northwest of Copper Hill is Little Copper Hill which produced 195 tonnes of $13.8 \%$ copper ore in 1906-1907 from narrow supergene enriched zones in skarn mineralisation (Erceg, 1992).

Golden Cross Operations Pty Ltd, who currently hold the property, were interested in developing a better understanding of the three dimensional form of the mineralisation with a view to evaluating a small scale mining option, of the high grade vein system.

An Induced Polarization (IP) survey, in conjunction with three dimensional inversion of the data, was considered the best way of resolving the problem.

\section{Geology}

The Copper Hill project is located on the northern end of the Molong volcanic rise. Intermediate to basic volcanics and volcanically derived sediments of the Lower Ordovician Fairbridge Volcanics are overlain by Middle Ordovician Reedy Creek Limestone. Conformably above this are quartzites, sandstones and andesites of the Upper Ordovician Cheesemans Creek Formation (Figure 1). The Ordovician sequence has been intruded by a diorite - quartz diorite - tonalite sequence, commonly referred to in the literature as a 'dacite porphyry' (Morrison, 1998). There are four discrete phases of intrusion, each with its own related hydrothermal alteration. Unconformably overlying the

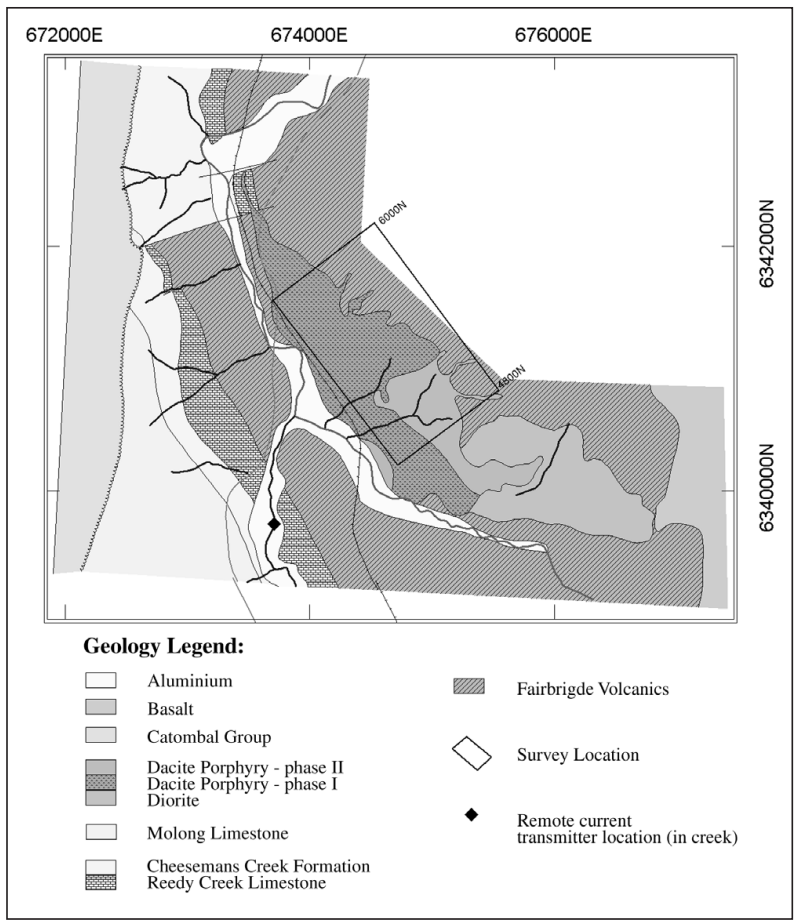

Fig. 1. Geology of the Copper hill area. (after Chivas and Nutter, 1975) 
Ordovician sequence are Siluro-Devonian limestones and sandstones of the Molong Limestone Formation which is in turn overlain by a sequence of conglomerates, shales and sandstones of the Catombal Group. The volcanic-sedimentary sequence has been cut by a series of northeasterly trending cross faults.

Copper Hill mineralisation occurs within the Fairbridge Volcanics accompanying all the vein and fracture fill intrusive phases of alteration. The highest grades at Copper Hill are located where the late stage structurally controlled basement gold mineralisation overprints an earlier strongly developed vein network (Morrison, 1998).

\section{Exploration}

Exploration for porphyry copper mineralisation commenced in 1966 when Anaconda Nickel Limited completed mapping, rockchip sampling, an IP survey and 7 core diamond drill holes. Anaconda estimated the porphyry system contained 134 million tonnes averaging $0.17 \%$ copper. Subsequent mapping, soil, rock and stream sampling by BHP Limited and Homestake Mining Ltd between 1982 and 1986 outlined widespread, though erratic, base metal and gold anomalies associated with quartz stockworks and silicified, linear fracture zones. Extensive follow up drilling by Homestake, Cyprus, Mimex (Logan, 1993), and Newcrest Mining (Haywood, 1996) since 1987 encountered mineralisation in most holes.

Structural studies (Morrison, 1998) have shown that gold and copper occur in structurally controlled fractures and quartz veins with up to two to three sets of fracture directions. Down hole geochemistry indicates four different structural regimes, differing markedly between holes as close as $200 \mathrm{~m}$ apart.

\section{METHOD AND RESULTS}

\section{Survey Design:}

A new IP survey design, based on a modified pole-dipole electrode array, was devised with the aim of achieving greater depth of investigation, efficient field operation and hence a high rate of data collection. The survey was required to produce broad coverage $(1.6 \mathrm{~km} \mathrm{x} 1.1 \mathrm{~km})$ and sufficient detail to resolve the geological problem.

The survey was designed so that a single $1.6 \mathrm{~km}$ line could be rolled out, surveyed, and rolled back in one day. This avoided wires being left out overnight and possibly being damaged by curious livestock.

Sixteen fixed dipole receiver electrodes were used per setup, using one operator and two Scintrex eight channel IPR12 receivers, positioned in the middle of the survey line. Each unit was connected to $8 \times 75 \mathrm{~m}$ receiver dipoles (Figure 2).

The layout of the multiple receivers was expedited by the use of pre wired 8 core receiver cables. These were wired in $75 \mathrm{~m}$ lengths with male and female screw sockets connecting each pair (Figure 3). With this design, the cables can be connected in any order with pin one on the nearest cable always going to the first pot and pin 8 to the furthest.

A single remote transmitter electrode was placed in the creek approximately $2 \mathrm{~km}$ from the survey grid and left in place for the duration of the survey. The wire was laid along creek beds and fences to protect it from animal interference. The moving transmitter electrode was moved through the receiver array from one end to the other at $25 \mathrm{~m}$ intervals.

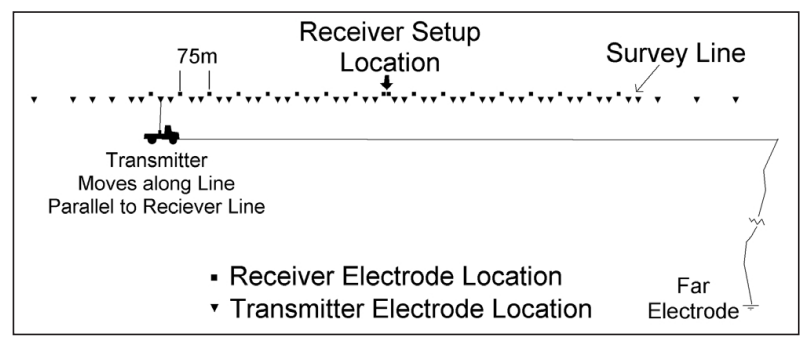

Fig. 2. Survey design consisting of 16 receiver dipoles and transmitter electrodes per line.



Fig. 3. Receiver Cable connections.

Transmitter electrodes were not placed near the receiver electrodes because all receiver dipoles were recording for all transmitter locations. The metal plate transmitter electrodes, $60 \mathrm{~cm}$ by $20 \mathrm{~cm}$, were laid in shallow trenches at $25 \mathrm{~m}$ intervals between the receiver electrodes. In order to extend the 3D model to the full width of the receiver array a further six transmitter electrodes were placed at 25, 50, 100, 150, 200 and $300 \mathrm{~m}$ from each end of the array, bringing the total to 44 transmitter electrodes per setup.

The pole-dipole geometry introduces EM coupling between the transmitter wire and the receiver array. To minimise this, the transmitter wire, connecting the pole electrode, was run $100 \mathrm{~m}$ perpendicular to the receiver line and connected to the mobile transmitter located on a vehicle. To further minimise the effects of EM coupling the 3D inversion only used data from channel 12, at $820 \mathrm{mSec}$ to $1050 \mathrm{mSec}$, of sufficiently late delay time to be minimally effected by EM coupling.

The transmitter electrodes were connected and readings recorded at each of the 16 receiver electrodes at each of the $25 \mathrm{~m}$ spaced transmitter electrodes then the truck moved $50 \mathrm{~m}$ down the line to the next transmitter pair location.

Figure 2 shows the layout of 16 receiver dipoles and 44 transmitter poles for a single survey line $1.6 \mathrm{~km}$ long. The survey produced 704 readings in one day, providing both broad coverage and high resolution. High data redundancy is built into this array so that the occasional noisy reading can be ignored.

\section{Data Editing:}

Eleven parallel survey lines of 704 readings, resulting in a total of 7744 readings, were surveyed in ten days. High redundancy in the data set allows for automated data editing to remove unreliable data points. Criteria for deletion were:

- an isolated negative chargeability,

- standard deviation of the chargeability was greater than $25 \%$ of the chargeability reading, and

- non-monotonic decrease in chargeability over time.

Approximately $8 \%$ of the total number of readings taken were deleted from the data set. 


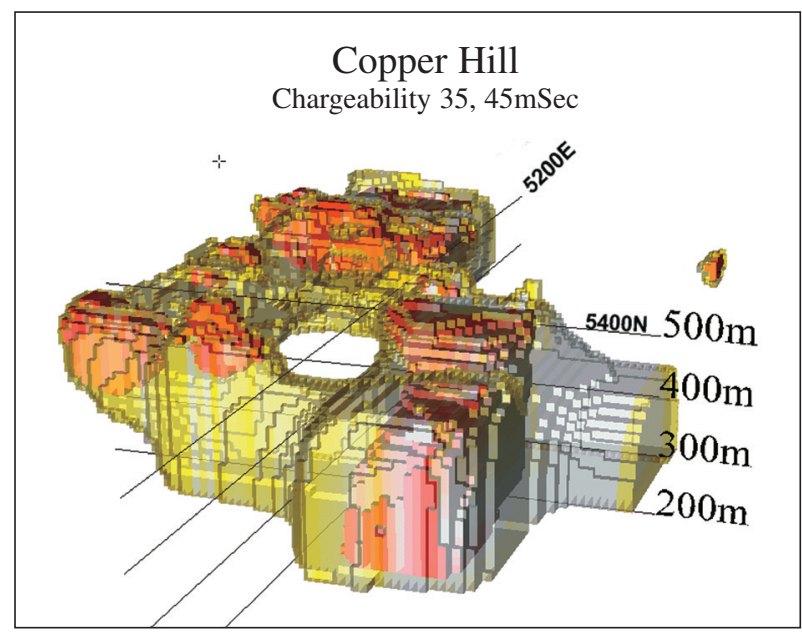

Fig. 4. 3D Chargeability IP model of Copper Hill with sensitivity controlling the colour saturation.

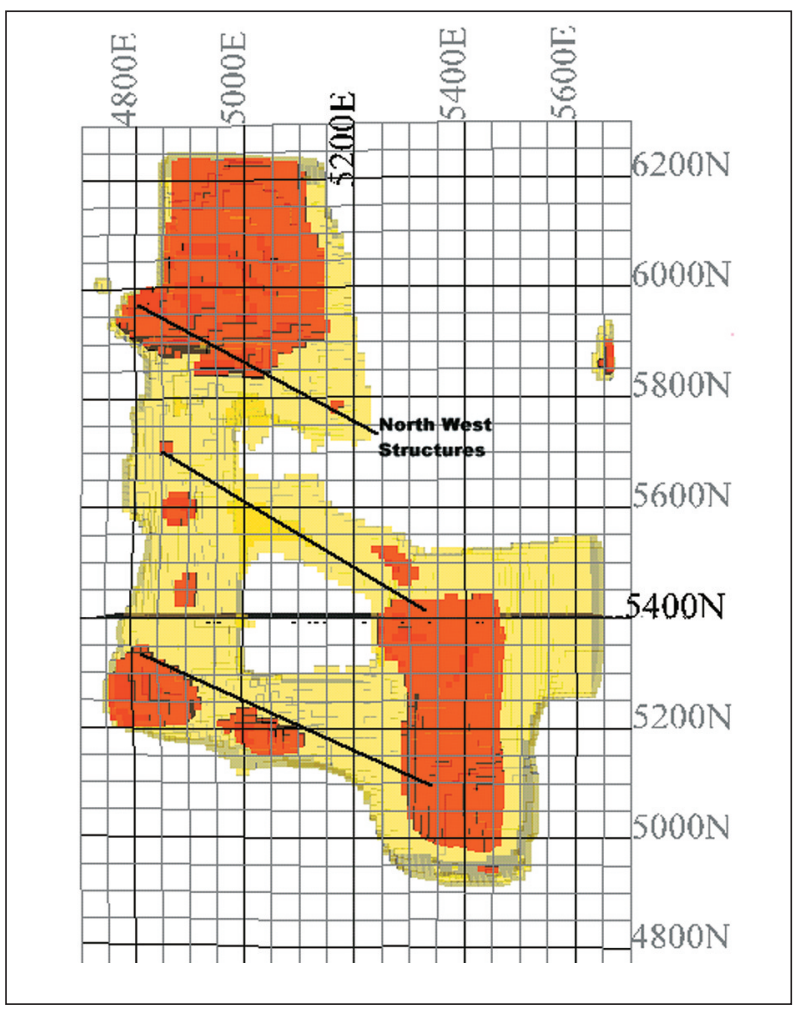

Fig. 5. Plan of 3D IP Chargeability Model. Yellow 35, Red 45 mV/V. Note the North West structures.

The edited data were inverted using Loke's 3D-inversion program (Loke, 1999 a,b) and inverted models of chargeability and resistivity displayed using 3D-visualisation software.

\section{Results:}

The sensitivity of the 3D inversion was studied before the chargeability results were interpreted. The inversion program produces sensitivity parameters which were integrated into the $3 \mathrm{D}$ visualisation model as colour saturation. This has the effect of making the colour paler in the areas that are less well defined, turning to white in the least well defined areas. It should be noted that the edge blocks will always be poorly defined because there is no information outside of these blocks. Figure 4 is a perspective view of the $3 \mathrm{D}$ model. These models do not represent the best visualisation of the data but do provide valuable information on the reliability of the data.

The 3D modeling of the chargeability defined two en-echelon north-south trends and two approximately east-west trends forming an annular zone of higher chargeability (Figure 5). This annular zone is crossed by several northwest trending structures, and possibly dips shallowly to the east and plunges to the north.

The western chargeability zone is shallow and has a clearly defined bottom surface, plunging to the east, see Figure 6 .

With the exception of Copper Hill and Buckleys Hill, which have near surface resistive highs possibly relating to the presence of a silica cap, the western chargeability zone is relatively conductive (Figure 7). Existing drilling has targeted the western shallow part of the north-south trends. The downhole geochemistry results correlate well with the high chargeability zones. Cyprus drill hole CHRC58, which intersected $217 \mathrm{~m}$ grading $1.67 \mathrm{~g} / \mathrm{t}$ gold and $0.72 \%$ copper is coincident with an IP zone of greater than $35 \mathrm{mV} / \mathrm{V}$. The defined lower surface of the chargeable zone is also coincident with the low assay results at depth in the existing drilling.

The eastern chargeability zone, characterised by high chargeability and high resistivity, does not outcrop, but can be correlated well with the mapped Fairbridge Volcanics. Very little drilling has penetrated this deeper, eastern zone.

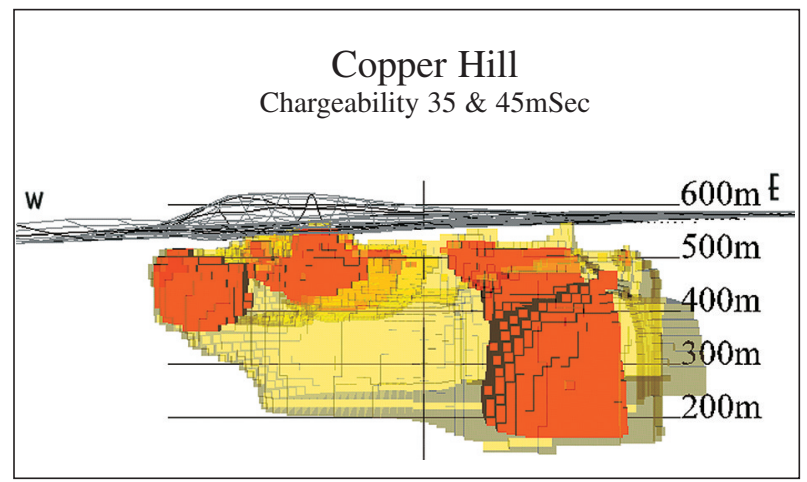

Fig. 6. Perspective section of 3D chargeability model looking north.

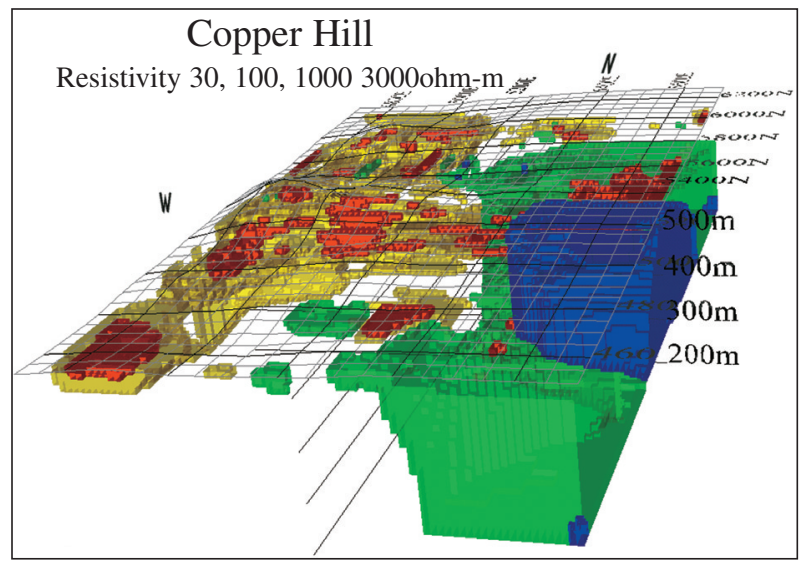

Fig. 7. Resistivity Model. Red low to blue high resistivity. the green and blue areas are coincident with the volcanics. 


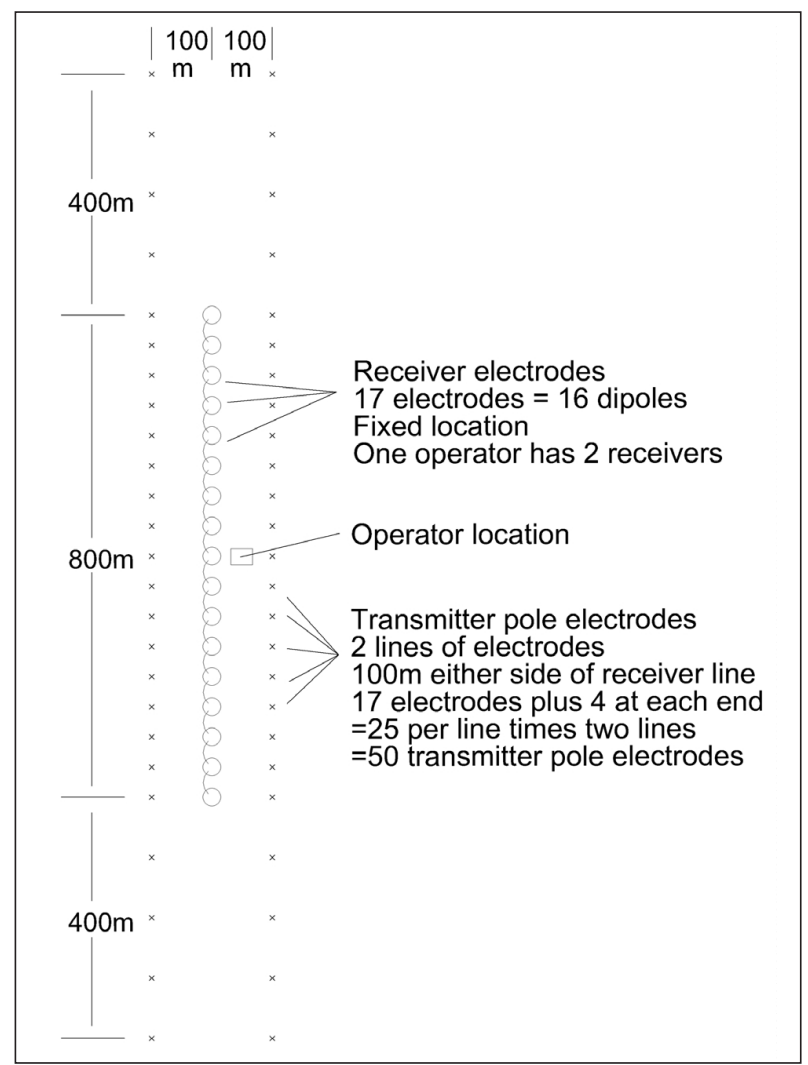

Fig. 8. Survey design with receivers off line.

\section{FURTHER WORK}

Considerable time was spent, during the survey, moving the transmitter electrodes, which involved moving the wires from the transmitter to the receiver line and back, a distance of $8.8 \mathrm{Km}$ (44 electrodes $* 2 * 100 \mathrm{~m}$ ) per setup.

It was postulated that the transmitter electrodes need not be located on the same line as the receivers, instead located on parallel lines, provided that the receiver reading opposite the current transmitter electrode was ignored, because they fall on or close to lines of equipotential. Operators could then survey two transmitter lines for each receiver line setup. See Figure 8 \& 9. It should also be possible to survey both transmitter lines in one day, thus maintaining to the original requirements of setting up and removing the receivers in one day.

This revised survey configuration was tried on another prospect with success.

One drawback to operating in this mode is that it is not possible for the operator to monitor the data collection along the line as it is collected. The operators can only monitor the decays and noise levels. At least 3 lines of data need to be collected to ensure it is geologically meaningful.

\section{CONCLUSIONS}

The use of 3D-inversion techniques made the survey technique viable. Conventional IP interpretation would be too complex for the new survey arrays described here.

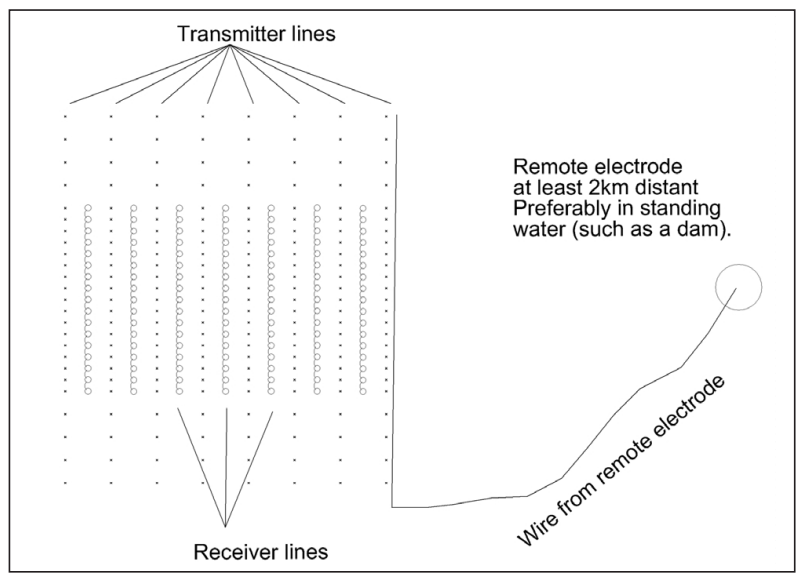

Fig. 9. Survey setup.

Uncertainties regarding structural trends at Copper Hill were resolved and understanding of the subsurface geology was improved by using 3D inversion of the IP data.

The new survey techniques were successful in obtaining high rates of data acquisition, increased target resolution and hence were very cost effective. They also provided greater depth of penetration, $(+500 \mathrm{~m})$ than conventional dipole-dipole surveys while retaining resolution. The survey at Copper Hill was designed for maximum resolution while the latter (Figure 9) survey was designed for greater depth of investigation and enhancement of $3 \mathrm{D}$ resolving capabilities.

\section{ACKNOWLEDGEMENTS}

The authors acknowledge Scintrex, Golden Cross Operations Pty Ltd, Arctan Services Pty Ltd for their contribution to the research in this paper and Stephen Mudge for comments \& editing this manuscript.

\section{REFERENCES}

Chivas, A.R and Nutter, A. H., 1975, Copper Hill Porphry-Copper Prospect. Knight, S.L. (ed), Economic Geology of Australia and Papua New Guinea vol I. Metals: Australasian Institute of Mining and Metallurgy Monograph No. 5, p 716-720.

Erceg, M., 1992, Exploration Licence 2290 - Copper Hill, Molong, NSW.: Annual Report to November 13, 1992 - Submitted as part of Special Circumstances Renewal. Cyprus Gold Australia Limited. Unpublished.

Haywood, S., 1996, Exploration Licence 2290 - Copper Hill, Molong, NSW.: Annual Report to November 17, 1995 - November 13, 1996. Newcrest Mining Limited. Unpublished.

Logan, R.G., 1993, Exploration Licence 2290 - Copper Hill, Molong, NSW.: Annual Report to November 13, 1993. MIM Exploration Pty Ltd. Unpublished.

Loke, M.H. and Baker R.D., 1996a. Rapid least-squares inversion of apparent resistivity pseudosections using a quasi-Newton method. Geophysical Prospecting, 44, 131-152.

Loke, M.H. and Baker R.D., 1996b. Practical Techniques for 3D resistivity surveys and data inversion. Geophysical Prospecting, 44, 499-523.

Loke M.H., 2001, RES3DINV - Rapid 3D Resistivity and IP Inversion using the least squares method. Geoelectrical Imaging 2D \& 3D. : Computer software manual. Geotomo Software, Malaysia.

Morrison, G.W., 1998, Copper Hill: Magmatic - Hydrothermal Evolution: Magmatic and Hydrothermal

Evolution of Intrusive Related gold Deposits. AMIRA P245 Final Report. Section $15 \mathrm{~A}$. 